\title{
Isolation and Efficient Maize Protoplast Transformation
}

Lina Gomez-Cano ${ }^{1}$, Fan Yang ${ }^{2, \$}$ and Erich Grotewold ${ }^{1, *}$

1Department of Biochemistry and Molecular Biology, Michigan State University, East Lansing, 48824, MI, United States; ${ }^{2}$ Center for Applied Plant Sciences (CAPS) and Department of Molecular Genetics, The Ohio State University, Columbus, 43210, OH, United States; ${ }^{\$}$ Current address: Benson Hill Biosystems, 1100 Corporate Square Dr, St. Louis, MO, 63132, USA

*For correspondence: grotewol@msu.edu

[Abstract] Establishing plant gene function and the study of gene expression regulation often require that genes (or gene variants) are introduced into plants and their activity somehow assayed. Some plants (e.g., Arabidopsis) are easily transformed, while for others (e.g., maize) making stable transgenic plants remains challenging, is expensive and time-consuming. An alternative solution to generating transgenic plants is to assay gene function transiently. In some plants, it is possible to do this by Agroinfiltration. We have adapted a maize protoplast isolation protocol that permits high-efficiency transformation by electroporation, irrespective of the genetic background. Transformed protoplasts have been used to assay gene function using metabolic profiling, to explore protein-DNA interactions using chromatin immunoprecipitation (ChIP), and to assay the activation of reporter constructs by transcription factors. Here, we describe the protocol for efficient maize protoplast isolation and transformation by electroporation.

Keywords: Maize, Protoplast, Electroporation

[Background] Maize (Zea mays) is one of the most cultivated crops in the world, with a productivity that continues to increase thanks to genetic advances and to improved agronomic practices (Haarhoff and Swanepoel, 2018). In addition to the grain, the stover is used for the production of biofuels and electricity (Trivedi et al., 2015). Maize is also an important model plant for fundamental research (Cone et al., 2002; Nannas and Dawe, 2015). While a large number of maize genes have been cloned and characterized, functional information on many genes is still lacking (Jin et al., 2017; Cao et al., 2018). One of the strategies most commonly used to determine gene function is the characterization of the phenotypes of loss-of-function mutants. Unless multiple alleles are available, the usual practice is to complement the mutants with the wild-type gene to confirm the nature of the mutation. When multiple candidate genes must be validated, in a plant like maize, this can become prohibitively expensive and very timeconsuming. In some instances, for example, to identify the gene responsible for a missing step in a biosynthetic pathway, transformation of protoplasts derived from the mutant with the candidate genes, combined if necessary with precursor feeding, can narrow down, or even identify, the responsible gene (Casas et al., 2016). We have also successfully used maize protoplast transformation to confirm transcription factor target genes (Yang et al., 2017), and to establish the organization of transcriptional complexes (Hernandez et al., 2007). We describe here a fast and simple protocol to generate and 
transform protoplasts from maize seedlings, irrespective of the genotype. This protocol is largely based on Sheen (1991 and 2001) and Jang and Sheen (1994).

\section{Materials and Reagents}

1. Pipette tips (Fisher brand, catalog number: 02707414)

2. Aluminum foil (Reynolds Kitchens, REYNOLDS WRAP, catalog number: 353224)

3. Filter paper (Fisher Scientific, catalog number: 34155)

4. Parafilm (Fisher Scientific, catalog number: 13-374-12)

5. $35 \mu \mathrm{m}$ Mesh (Carolina biological supplies, catalog number: 652222R)

6. Single Edge Blade 009 (Accutec blades, catalog number: 94-0491-0000)

7. Glass cutting board

8. Electroporation Cuvettes (BIO-RAD, catalog number: 1652088)

9. $50 \mathrm{ml}$ Falcon tubes (Thermo Fisher, catalog number: 14-432-22)

10. $1.7 \mathrm{ml}$ Microcentrifuge tubes (Fisher Scientific, catalog number: 21-402-905)

11. 25 seeds of maize

12. Cellulase "ONOZUKA" RS (Yakult Pharmaceutical Industry Co., Ltd)

13. Macerozyme R-10 (Yakult Pharmaceutical Industry Co., Ltd)

14. D-Mannitol (Fisher Scientific, catalog number: M120-3)

15. Potassium Chloride (KCl) (Sigma-Aldrich, catalog number: P3911)

16. MES free acid monohydrate (GoldBIO, catalog number: M-090-500)

17. Calcium chloride $\left(\mathrm{CaCl}_{2}\right)$ (Sigma-Aldrich, catalog number: $\left.\mathrm{C} 2661\right)$.

18. Bovine serum albumin (BSA) (Sigma-Aldrich, catalog number: A3059)

19. Maxiprep Kit (Invitrogen, catalog number: K210017)

20. Protoplasts buffer (see Recipes)

21. Enzyme suspension (see Recipes)

\section{Equipment}

1. Flask with side arm

2. Pipettes

3. Hemocytometer (Hausser \& Son LEVY ULTRA PLANE Improved NEUBAUER MINT)

4. Centrifuge (Thermo Scientific ${ }^{\mathrm{TM}}$ Sorvall ${ }^{\mathrm{TM}}$ Legend $^{\mathrm{TM}} \mathrm{XTR}$ )

5. Electroporator (BTX electro-square-Porator ECM 830)

6. Fluorescence microscope (Leica DM IL LED Inverted Phase Contrast Microscope with the camera Leica DFC 3000 G)

7. Optical microscope (Reichert Scientific Jung microscope series 150)

8. Refrigerated incubator (Fisher Scientific, catalog number: 3720A)

9. Benchtop Orbital Shakers (Fisher Scientific, catalog number: SHKE3000) 
10. Microcentrifuge (Thermo Scientific, model: Sorvall ${ }^{T M}$ Legend $^{T M}$ Micro 17, catalog number: 75002403)

11. Water bath (VWR, model: 1230)

\section{Procedure}

A. Etiolated plant growth

1. Soak maize seeds in water $\mathrm{O} / \mathrm{N}$ at room temperature.

2. Transfer the seeds to wet filter papers in a covered beaker for 2 days at room temperature.

3. Move the germinated seeds to soil and grow in an incubator in the dark for $10-12$ days at $26^{\circ} \mathrm{C}$, $60 \%$ relative humidity.

Note: Etiolated maize leaves are used because green leaves are more brittle (Sheen, 2001), and chloroplasts interfere with the detection of the GFP signal.

B. Protoplasts buffer preparation (Total volume: $50 \mathrm{ml}$ )

In a Falcon tube, mix: $48.75 \mathrm{ml}$ of $0.6 \mathrm{M} \mathrm{D}-M a n n i t o l, 0.25 \mathrm{ml}$ of $2 \mathrm{M} \mathrm{KCl}, 1 \mathrm{ml}$ of $0.5 \mathrm{M} \mathrm{MES} \mathrm{(pH} \mathrm{5.7).}$ Note: Keep the buffer on ice.

C. Protoplast Isolation

1. Enzyme suspension: Weight $0.3 \mathrm{~g}$ of cellulase and $0.07 \mathrm{~g}$ of macerozyme in a $50 \mathrm{ml}$ Falcon tube. Add $10 \mathrm{ml}$ of protoplasts buffer and disperse along the wall of the tube using a spatula or glass rod.

Note: Do not vortex. Avoid at all times the foam production, it can affect the activity of the enzyme.

2. Incubate the enzyme suspension in a water bath for $5 \mathrm{~min}$ at $55^{\circ} \mathrm{C}$, and then cool on ice for 5 $\min$.

3. Add $50 \mu \mathrm{l} 1 \mathrm{M} \mathrm{CaCl}_{2}$ and $100 \mu \mathrm{l} 10 \% \mathrm{BSA}$ to the enzyme suspension, and mix gently. Keep in the dark (by wrapping the tube in aluminum foil) on ice.

4. Transfer the enzyme suspension to a flask with a vacuum arm, and keep in the dark (by wrapping the flask with aluminum foil).

5. Cut 12 leaves from the 10-12 day-old maize etiolated seedlings. Select the second in each seedling when they are 10-15 cm higher than the first leaf (Figure 1A). Stack the leaves on top of each other and discard of $1 / 3$ from each end, keeping only the middle part $(6-8 \mathrm{~cm})$.

6. Using a new (never used) razor blade cut the leaves in very fine strips on the cutting glass board (Figure 1B) (Usually three new blades are used). Make sure you do not squeeze/damage the leaves while cutting. As you cut them, add the cut leaves to the flask that contain the enzyme suspension. 


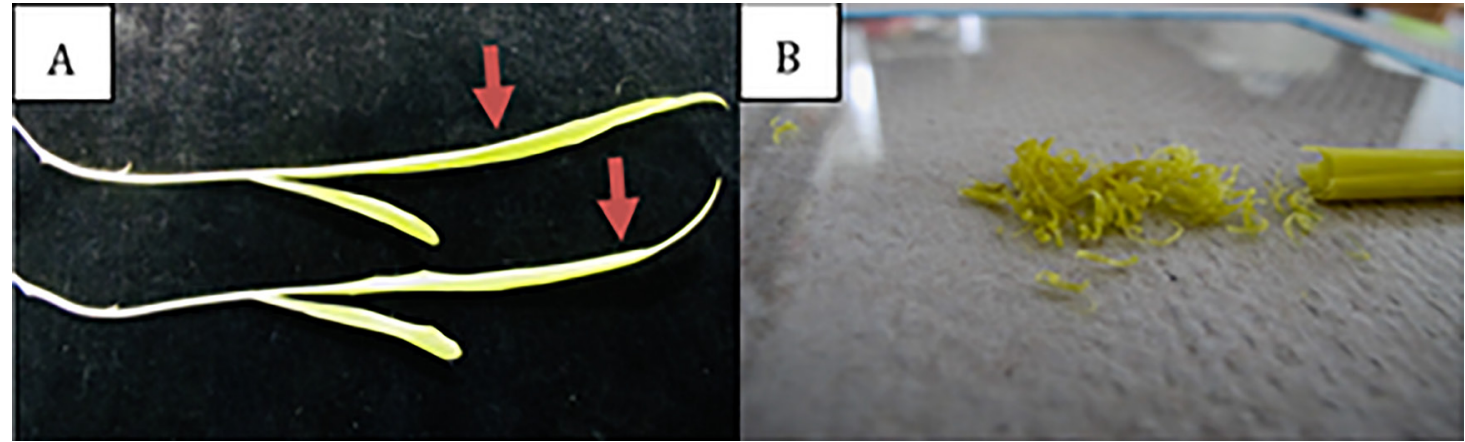

Figure 1. Etiolated maize leaves. A. Second leaves from etiolated 10-day-old maize plants. B. Cut strips on the glass board.

7. Vacuum the enzyme suspension containing the cut leaves at $20 \mathrm{~mm} \mathrm{Hg}$ for $40 \mathrm{~min}$ to allow sufficient infiltration. Keep in the dark as much as possible. Note: A central vacuum line is used.

8. Cover the holes in the flask with Parafilm and shake at $60 \mathrm{rpm}$ for $3 \mathrm{~h}$ at $26{ }^{\circ} \mathrm{C}$ to digest the cell walls. Keep in the dark.

9. Shake at $90 \mathrm{rpm}$ for $5 \mathrm{~min}$ the enzyme suspension to release the protoplasts.

10. Filter the enzyme suspension containing the protoplasts into a $50 \mathrm{ml}$ Falcon tube using a $35 \mu \mathrm{m}$ nylon mesh.

11. Collect the protoplasts by centrifugation at $150 \times \mathrm{g}$ for $1.5 \mathrm{~min}$ at room temperature, and then remove the supernatant using a vacuum system.

12. Wash protoplasts twice with $10 \mathrm{ml}$ protoplasts buffer. Spin at $150 \times \mathrm{g}$ for $1.5 \mathrm{~min}$ after each wash, and discard the supernatant.

Note: Be very careful when resuspending the protoplasts, do not vortex, mix by inverting the tube gently.

13. Finally, resuspend the protoplast in 2-3 $\mathrm{ml}$ protoplasts buffer. Keep on ice.

D. Counting protoplast

Load $15 \mu \mathrm{l}$ of the protoplast suspension into a hemocytometer and count cells under a light microscope using the $20 x$ objective (Figure 2 ). The expectation is to obtain $\sim 10^{5}$ protoplasts $/ \mathrm{ml}$ ( 8 protoplasts per square). 


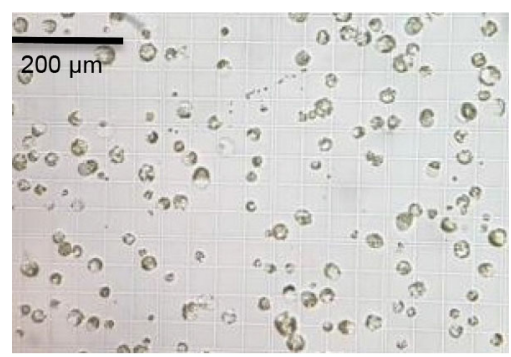

Figure 2. Protoplasts isolated from etiolated maize leaves. Image was taken at 20x magnification using a Reichert Scientific Jung microscope, and the bar (top left corner) corresponds to $200 \mu \mathrm{m}$.

E. Protoplast transformation

1. Plasmid DNA preparation from E. coli cells harboring the relevant plasmids: Plasmid DNA is isolated using the Invitrogen Kit (following the protocol provided by Invitrogen), which yields good-quality DNA with values $A_{260} / A_{280}=1.7-2.0$. Dilute $15-40 \mu$ DNA in protoplasts buffer and take to a total volume of $150 \mu \mathrm{l}$.

2. Electroporation: Transfer the $150 \mu$ of DNA suspension to the cuvette, and add $150 \mu$ l protoplast suspension (1-2 $\left.\times 10^{5} / \mathrm{ml}\right)$. Mix very gently. The optimal electroporation conditions are $5 \mathrm{~ms}, 200$ $\mu \mathrm{F}(0.5-1 \mathrm{kV} / \mathrm{cm})$ and one pulse. For instance, $100 \mathrm{~V}$ would be used to achieve $0.75 \mathrm{kV} / \mathrm{cm}$ if a $2 \mathrm{~mm}$ cuvette is used.

3. After electroporation, place the cuvette back on ice, add $700 \mu \mathrm{l}$ of protoplasts buffer, mix very gently and transfer to a fresh $1.7 \mathrm{ml}$ Eppendorf tube.

4. Store tubes for 18-22 $\mathrm{h}$ at room temperature in the dark, laying on the side.

F. Transformation efficiency

Transformation efficiency is estimated as a percentage of transformed cells following GFP expression (Figure 3), for example when driven from a constitutive promoter, such as the CaMV35 promoter (p35S::GFP). Using the equation:

$$
\frac{\# \text { protoplast expressing GFP }}{\text { total \# protoplast }} * 100=\% \text { trasnformation efficiency }
$$

The transformation efficiency can reach $30-70 \%$ irrespective of the genotype. 


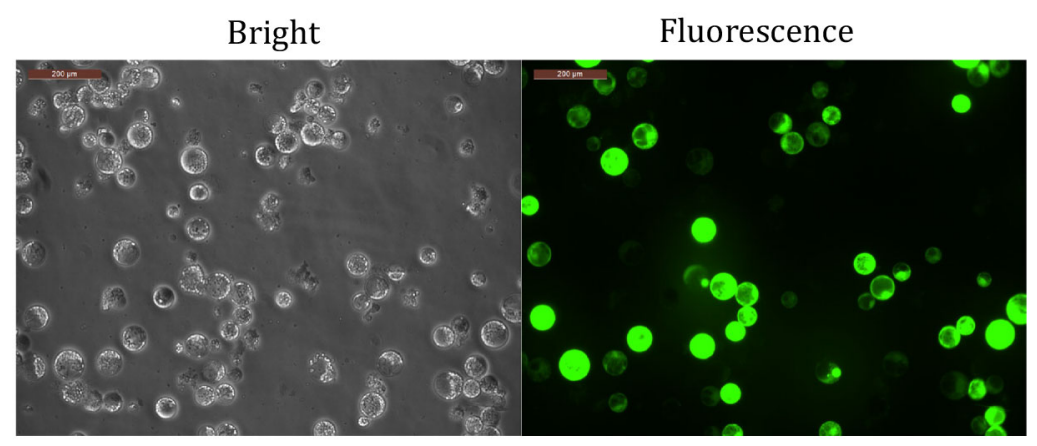

Figure 3. Protoplasts were prepared from etiolated maize leaves and transformed as described in "Procedure" with a plasmid expressing GFP. Images were taken at 20x magnification, and the bar (top left corner) corresponds to $200 \mu \mathrm{m}$.

\section{Recipes}

1. Protoplasts buffer

0.6 M D-Mannitol

$2 \mathrm{M} \mathrm{KCl}$

$0.5 \mathrm{M} \mathrm{MES}(\mathrm{pH} 5.7)$

2. Enzyme suspension

Protoplasts buffer

$1 \mathrm{M} \mathrm{CaCl}_{2}$

$10 \%$ BSA

$3 \%$ Cellulase "ONOZUKA" RS

$0.7 \%$ Macerozyme R-10

\section{Acknowledgments}

We are indebted to Dr. Jyan-Chyun (JC) Jang (The Ohio State University) for his guidance and patience over the years in teaching members of our lab how to make maize protoplasts. We also thank Dr. Wei Li for her assistance in helping standardize earlier versions of the method. This project was supported in part by the Agriculture and Food Research Initiative (AFRI) competitive award number 2018-67013-27424 from the USDA National Institute of Food and Agriculture, and by grant NSF MCB-1513807. This protocol is largely based on Sheen (1991 and 2001) and Jang and Sheen (1994).

We declare no conflicts of interest or competing interests. 


\section{References}

1. Cao, L., Lu, X., Zhang, P., Ku, L., Wang, G., Yuan, Z., Zhang, X., Cui, J., Han, J., Liu, Y., Cao, Y., Wei, L. and Wang, T. (2018). Regulatory networks of gene expression in maize (Zea mays) under drought stress and re-watering. bioRxiv: 361964.

2. Casas, M. I., Falcone-Ferreyra, M. L., Jiang, N., Mejia-Guerra, M. K., Rodriguez, E., Wilson, T., Engelmeier, J., Casati, P. and Grotewold, E. (2016). Identification and characterization of maize salmon silks genes involved in insecticidal maysin biosynthesis. Plant Cell 28(6): 1297-1309.

3. Cone, K. C., McMullen, M. D., Bi, I. V., Davis, G. L., Yim, Y. S., Gardiner, J. M., Polacco, M. L., Sanchez-Villeda, H., Fang, Z., Schroeder, S. G., Havermann, S. A., Bowers, J. E., Paterson, A. H., Soderlund, C. A., Engler, F. W., Wing, R. A. and Coe, E. H., Jr. (2002). Genetic, physical, and informatics resources for maize. On the road to an integrated map. Plant Physiol 130(4): 1598-1605.

4. Haarhoff, S. J. and Swanepoel, P. A. (2018). Plant population and maize grain yield: A global systematic review of rainfed trials. Crop Science 58:1819-1829.

5. Hernandez, J. M., Feller, A., Morohashi, K., Frame, K. and Grotewold, E. (2007). The basic helix loop helix domain of maize $\mathrm{R}$ links transcriptional regulation and histone modifications by recruitment of an EMSY-related factor. Proc Natl Acad Sci U S A 104(43): 17222-17227.

6. Jang, J. C. and Sheen, J. (1994). Sugar sensing in higher plants. Plant Cell 6(11): 1665-1679.

7. Jin, M., Zhang, X., Zhao, M., Deng, M., Du, Y., Zhou, Y., Wang, S., Tohge, T., Fernie, A. R., Willmitzer, L., Brotman, Y., Yan, J. and Wen, W. (2017). Integrated genomics-based mapping reveals the genetics underlying maize flavonoid biosynthesis. BMC Plant Biol 17(1): 17.

8. Nannas, N. J. and Dawe, R. K. (2015). Genetic and genomic toolbox of Zea mays. Genetics 199(3): 655-669.

9. Sheen, J. (1991). Molecular mechanisms underlying the differential expression of maize pyruvate, orthophosphate dikinase genes. Plant Cell 3(3): 225-245.

10. Sheen, J. (2001). Signal transduction in maize and Arabidopsis mesophyll protoplasts. Plant Physiol 127(4): 1466-1475.

11. Trivedi, P., Malina, R. and Barrett, S. R. H. (2015). Environmental and economic tradeoffs of using corn stover for liquid fuels and power production. Energy Environ Sci 8(5): 1428-1437.

12. Yang, F., Li, W., Jiang, N., Yu, H., Morohashi, K., Ouma, W. Z., Morales-Mantilla, D. E., GomezCano, F. A., Mukundi, E., Prada-Salcedo, L. D., Velazquez, R. A., Valentin, J., Mejia-Guerra, M. K., Gray, J., Doseff, A. I. and Grotewold, E. (2017). A maize gene regulatory network for phenolic metabolism. Mol Plant 10(3): 498-515. 